\title{
Evaluación de la Soldabilidad de Rieles Endurecidos Grado R350HT para la Reparación de Ferrovías con Recargues Superficiales
}

\author{
Henry León-Henao ${ }^{1}$ (D) , Álvaro Diego Bedoya-Zapata ${ }^{1}$, Carlos Franco-Rendón ${ }^{1}$, Juan Felipe Santa ${ }^{1,2}$ (D) , Jorge Enrique Giraldo Barrada ${ }^{1}$ (D) \\ ${ }^{1}$ Universidad Nacional de Colombia, Medellín, Colombia. \\ ${ }^{2}$ Facultad de ingenierías, Instituto Tecnológico Metropolitano, Medellín, Colombia.
}

Como citar: Léon-Henao H, Bedoya-Zapata AD, Franco-Rendón C, Santa JF, Giraldo Barrada JE. Evaluación de la Soldabilidad de Rieles Endurecidos Grado R350HT para la Reparación de Ferrovías con Recargues Superficiales. Soldagem \& Inspeção. 2019;25:e2537. https://doi.org/10.1590/0104-9224/SI25.37

\begin{abstract}
Resumen: La estructura ferroviaria de los sistemas Metro está típicamente compuesta de rieles de acero que, cuando aparecen defectos, se deben reparar en sitio mediante procesos de soldeo. Este trabajo muestra el desarrollo de procedimientos de soldeo para reparar rieles tratados térmicamente grado R350HT con recargues superficiales y la evaluación de su soldabilidad usando los lineamientos de la norma UNE-EN 15594:2009. Se realizaron pruebas del tipo cordón único, capa única y multicapas sobre secciones de rieles con perfil 54E1 usando electrodos de SMAW DUR 300, DUR 350 y E11018. Las evaluaciones de las soldaduras se realizaron para que las propiedades mecánicas de las soldaduras superficiales de reparación se aproximen a las del riel R350HT con miras a garantizar que su desempeño en servicio sea también similar. Los resultados de las pruebas de laboratorio indican que únicamente el electrodo DUR 350 podría ser usado como consumible para reparar superficies de rodadura de rieles grado R350HT ya que cumple los criterios de aceptación para cordón único, capa única y multicapas establecidos en las normas UNE-EN 13674-1:2012 y 15594:2009.
\end{abstract}

Palabras clave: Soldabilidad; R350HT; Soldadura superficial; Capa de soldadura; Superficie de rodadura.

\section{Avaliação da Soldabilidade dos Trilhos Endurecidos Grado R350HT para a Reparação de Ferrovias com Recargos Superficiais}

\begin{abstract}
Resumo: A estrutura de ferrovias dos sistemas Metro é normalmente composto do trilho de aço que, quando os defeitos aparecem, eles devem ser reparados no local usando processos de soldagem. Este trabalho mostra o desenvolvimento de procedimentos de soldagem para reparar trilhos tratados termicamente R350HT com recargas de superfície e a avaliação de sua soldabilidade usando as diretrizes da norma UNE-EN 15594: 2009. Testes de cordão único, camada única e multicamada foram realizados em seções de trilho de perfil 54E1 usando eletrodos SMAW DUR 300, DUR 350 e E11018. A avaliação das soldas foi realizada para que as propriedades mecânicas das soldas da superfície de reparo se aproximassem das do trilho (metal de base), a fim de garantir que seu desempenho em serviço também seja semelhante. Os resultados dos testes de laboratório indicam que apenas o eletrodo DUR 350 pode ser usado como consumível para reparar superfícies de trilhos de grade R350HT, pois atende aos critérios de aceitação para trilhos de cordão único, camada única e multicamadas estabelecidos nas normas UNE-EN 13674-1:2012 e 15594: 2009.
\end{abstract}

Palavras-chave: Soldabilidade; R350HT; Solda superficial; Camada de soldagem; Superfície de rolamento.

\section{INTRODUCCIÓN}

La estructura ferroviaria de los sistemas metro está típicamente compuesta de rieles producidos de acuerdo con la norma UNE-EN 13674-1 y, dependiendo de sus condiciones de servicio, puede utilizar diversos perfiles dentro de los cuales son típicos los carriles con perfil 54E1, conocido en el pasado como UIC 54 [1]. Los rieles endurecidos mediante tratamiento térmico han venido reemplazando a los rieles de grados estándar que tienen una dureza aproximada de $260 \mathrm{HB}$ en aplicaciones donde el desgaste por fatiga superficial se vuelve una característica importante [2-4]. Algunos grados de rieles endurecidos son el R350HT y el R400HT con durezas aproximadas de 350 y $450 \mathrm{HB}$, respectivamente. Los rieles grado R350HT se usan ampliamente en las curvas de los carriles debido a que poseen una resistencia al desgaste superior $[5,6,4,7,8]$.

Durante la operación de los sistemas ferroviarios se pueden producir diversos tipos de defectos en la superficie de rodadura tales como grietas ("head checks"), desprendimientos localizados de material ("spalling"), deformación plástica, 
grandes desprendimientos localizados causados por fatiga superficial ("squats" o "studs"), entre otros. La Figura 1 muestra fotografías de algunos de los defectos que se pueden presentar en la superficie de rodadura.

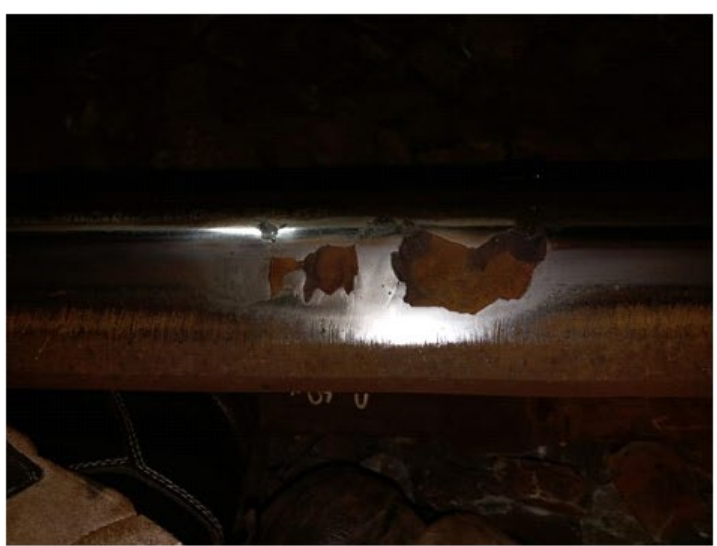

A. Ejemplo 1 de "squats" detectados en campo en la superficie de rodadura del riel.

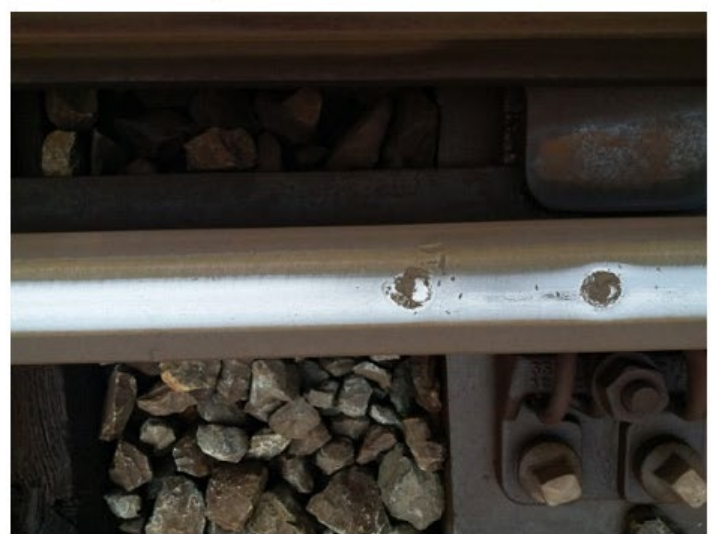

C. Ejemplo 2 de "squats" detectados en campo.
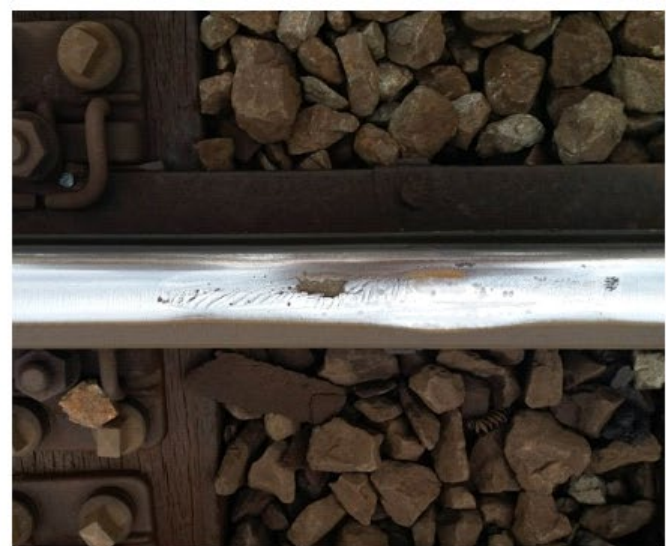

B. Grietas ("head checks") y desprendimientos localizados.

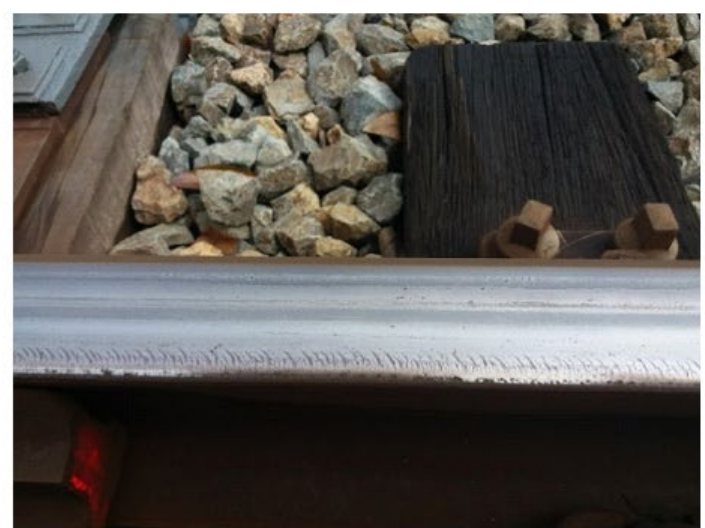

D. Grietas ("head checks").

Figura 1. Defectos típicos encontrados en rieles de sistemas ferroviarios.

Los países en vías de desarrollo no producen rieles por la baja cantidad de sistemas ferroviarios disponibles para su consumo. De acuerdo con lo anterior, cuando se presentan defectos superficiales en los carriles, se hace necesario realizar la reparación localizada de los rieles usando procesos de soldeo con el fin de incrementar su vida útil. Estos defectos se remueven con abrasivos y se reparan, normalmente, mediante la aplicación de soldaduras superficiales con proceso de soldeo al arco eléctrico SMAW. Algunas normas como la AWS D15.2:2003 [9] y la RENFE NRV 3-0-3.1 [10] presentan diversas recomendaciones con buenas prácticas para realizar reparaciones de carriles. La norma UNE-EN 15594:2009 considera la reparación de carriles por arco eléctrico como un proceso especial y establece un sistema para la aprobación (calificación o validación) de consumibles y de procedimientos (WPSs) para evitar fallos graves en el soldeo de reparación de una vía [11]. Esta norma indica que el organismo de certificación debe emitir una "declaración de soldabilidad" fundamentada en los resultados de la ejecución de varios ensayos y pruebas de soldabilidad con el grado de riel y los consumibles de soldadura.

Debido a que no se conoce certeramente si los materiales de aporte comerciales para la reparación de cabezas de rieles endurecidos resultan adecuados para la aplicación, es decir, que las soldaduras de los recargues superficiales obtenidos tengan aproximadamente las mismas propiedades mecánicas y metalúrgicas del riel, resulta necesario realizar las pruebas de laboratorio indicadas por la norma UNE-EN 15594:2009 para aprobar el consumible y el WPS para recuperaciones dimensionales de campo y garantizar el éxito de las reparaciones. En la Figura 2 se presenta el modelo de aprobación del consumible y del procedimiento de soldeo preliminar (pWPS) establecido por la norma UNE-EN 15594:2009. 


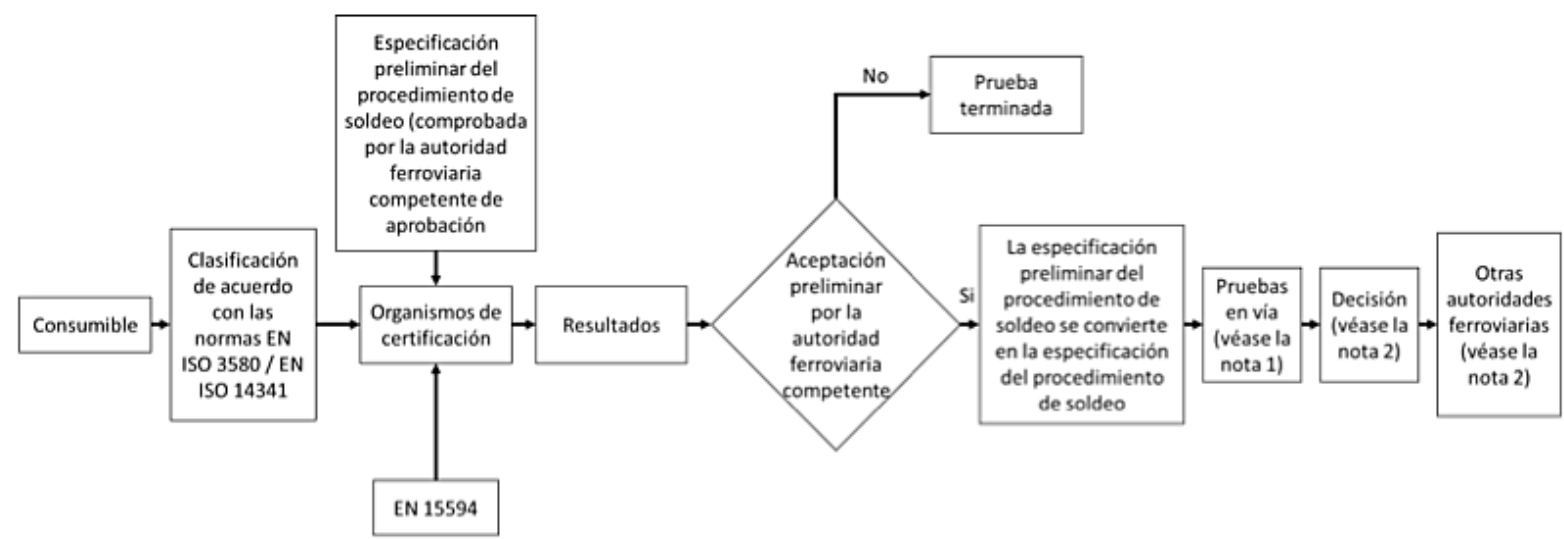

NOTA 1 Estas pruebas en vía las lleva a cabo la autoridad ferroviaria competente

NOTA 2 La autoridad ferroviaria competente debe emitir un certificado de aprobación si la prueba en vía tiene éxito.

NOTA 3 Otras autoridades ferroviarias pueden exigir más ensayos para verificar la idoneidad para condiciones operativas o de servicio especiales o técnicas de depósito

Figura 2. Diagrama de flujo del proceso de aprobación de consumibles y pWPSs hasta la etapa de pruebas en vía (Adaptado de la norma UNE-EN 15594) [11].

En este trabajo se evaluó la soldabilidad de rieles endurecidos grado R350HT y perfil 54E1 usando proceso SMAW con electrodos DUR 300, DUR 350 y E11018 de acuerdo con el modelo y los criterios de aceptación de la norma UNE-EN 15594:2009. Debido a la naturaleza sui géneris del proceso de aprobación de consumibles y WPSs de la norma UNE-EN 15594, en este estudio se describirá con detalle la metodología establecida por esta norma para mostrarle al personal de soldadura (ingenieros e inspectores) su particular modo de aplicación que difiere de la forma usual de calificación de WPSs. Para lo anterior, se realizaron pruebas de soldadura de cordón único, capa única y multicapas. Al final de este proceso se llega a una "declaración de soldabilidad" con la que se aprueban tanto los consumibles como el procedimiento de soldeo para garantizar que las propiedades mecánicas de las soldaduras superficiales de reparación se acercan a las de los rieles (metal base) y que su desempeño en servicio será, por lo tanto, similar. Las pruebas en vía de las soldaduras descritas en la Figura 2 están en proceso de programación, pero aún no se han realizado. Tampoco se evaluaron las propiedades mecánicas de impacto como ensayos Charpy o de $\mathrm{K}_{\mathrm{IC}}$ ya que no estaban contempladas en la norma.

\section{PROCEDIMIENTO EXPERIMENTAL}

\subsection{Ensayos de laboratorio establecidos en la norma UNE-EN 15594:2009}

La norma UNE-EN 15594:2009 establece tres etapas sucesivas para la aprobación de consumibles y procedimientos: (1) Pruebas de cordón único, (2) pruebas de capa única y (3) pruebas multicapas. Cada etapa de prueba es un prerrequisito indispensable para la siguiente, es decir, que si un consumible/WPS no pasa la prueba de cordón único, no puede probarse en las siguientes de capa única y multicapas, y si no pasa la de capa única no se prueba en multicapas. De los cupones de cada prueba se extraen probetas para diferentes tipos de ensayos de laboratorio que son: examen visual (VT), líquidos penetrantes (PT), dureza, macroataque, microestructura y composición química. Los ensayos de cada conjunto de pruebas de soldadura se muestran en la Tabla 1. La metodología de la norma UNE-EN 15594:2009 seguida para el caso particular de este estudio se describe en la siguiente sección.

Con el propósito de extraer la mayor información posible de la interacción de los metales de aporte con el riel R350HT se hicieron ensayos adicionales a los que contempla la norma UNE EN 15594:2009 tales como: análisis de composición química del metal fundido (cordón) sobre el riel, macroataque para estimar la dilución a partir de las regiones de la soldadura (metal fundido, zona afectada térmicamente -ZAT- y metal base fundido), microscopía para revelar la microestructura en cada región de la soldadura y perfiles de dureza del metal fundido y la ZAT.

Tabla 1. Ensayos realizados para cada una de las etapas descritas en la norma UNE-EN 15594:2009.

\begin{tabular}{cccccc}
\hline $\begin{array}{c}\text { Tipo de prueba de } \\
\text { soldadura }\end{array}$ & VT + PT & $\begin{array}{c}\text { Composición } \\
\text { química }\end{array}$ & Macroataque & Microestructura & Dureza \\
Cordón único & $X$ & N.A. & N.A. & N.A. & N.A. \\
Capa única & $X$ & N.A. & $X$ & $X$ & $X$ \\
Multicapas & $X$ & $X$ & $X$ & $X$ & $X$ \\
\hline
\end{tabular}

Nota: N.A.= No aplica 
La inspección visual y los líquidos penetrantes se hicieron de acuerdo con los lineamientos los artículos 6 y 9 de la Sección $\mathrm{V}$ del Código ASME Boiler and Pressure Vessel Code [12] y se evaluaron con los criterios de aceptación y rechazo de la norma UNEEN 15594:2009.

Para estimar la composición química de los consumibles sin dilución se hicieron soldaduras superficiales con cada electrodo sobre platinas de acero ASTM A36 hasta obtener un recargue con un espesor mayor que $16 \mathrm{~mm}$ de acuerdo con la norma AWS A5.13:2000. Una vez obtenido el cupón de prueba, se realizó un amolado, pulido y limpieza de las superficies para realizar la medición de composición química por el método de espectrometría de emisión óptica con un equipo BRUKER Q8 MAGELLAN con patrón ARMI IARM 30B; BAS 434/1 y BAS 432/1.

Las secciones longitudinales y transversales de las soldaduras se pulieron con papel de abrasivo hasta granulometría 1000 y se les dio un acabado para metalografía con partículas de alúmina de $12.5 \mu \mathrm{m}$ y de diamante de $1 \mu \mathrm{m}$. Las probetas se atacaron con Nital 2\% (110 ml de alcohol etílico $+2 \mathrm{ml}$ de ácido nítrico). La microestructura se analizó utilizando microscopía óptica en un microscopio óptico NIKON Eclipse. La dureza de las muestras se midió en un durómetro DiaTestor 2Rc fabricado por Otto Wolpert-Werke con una carga de $30.25 \mathrm{kgf}$.

\subsection{Material base}

Se utilizó un riel endurecido grado R350HT con perfil 54E1 producido bajo la norma UNE-EN 13674-1:2012 [13]. La composición química y las propiedades mecánicas del riel dadas por la norma UNE-EN 13764-1:2012 y por el certificado de pruebas de materiales del productor (MTR) para este grado de acero se resumen en la Tabla 2 incluyendo, además, la composición química determinada por espectrometría de gases.

Tabla 2. Composición química y propiedades mecánicas del riel grado R350HT con perfil 54E1 dadas por la norma UNE-EN 13674-1:2012, por el MTR del productor y por espectrometría.

\begin{tabular}{|c|c|c|c|c|c|c|c|c|c|c|c|c|c|}
\hline \multirow[b]{2}{*}{ MATERIAL } & \multicolumn{9}{|c|}{ ELEMENTOS DE ALEACIÓN } & \multicolumn{4}{|c|}{ PROPIEDADES MECÁNICAS } \\
\hline & $\% \mathrm{C}$ & \%Al & $\% \mathrm{~V}$ & $\% N$ & \%Si & $\% M n$ & $\% \mathrm{P}$ & $\% S$ & $\% \mathrm{Cr}$ & $\begin{array}{c}\sigma_{\mathrm{t}} \\
(\mathrm{ksi})\end{array}$ & $E(\%)$ & $\begin{array}{c}\text { Dureza } \\
\text { (HB) }\end{array}$ & $\mathrm{K}_{\mathrm{IC}}$ \\
\hline Riel 350HT & $\begin{array}{l}0.7- \\
0.82\end{array}$ & $\leq 0.004$ & $\leq 0.03$ & $\leq 0.010$ & $\begin{array}{l}0.13- \\
0.40\end{array}$ & $\begin{array}{c}0.65- \\
1.25\end{array}$ & $\leq 0.025$ & $\leq 0.030$ & $\leq 0.15$ & 170 & 9 & $350-390$ & 32 \\
\hline MTR & 0.784 & --- & 0.003 & --- & 0.417 & 1.15 & 0.014 & 0.007 & 0.102 & 180 & 10.2 & 358 & --- \\
\hline Prueba & 0.739 & --- & 0.001 & --- & 0.453 & 1.198 & 0.016 & 0.013 & 0.085 & --- & --- & --- & --- \\
\hline
\end{tabular}

\subsection{Especificación preliminar de procedimiento de soldeo (pWPS)}

Los parámetros del pWPS se definieron siguiendo las indicaciones de los productores de los electrodos y, para la temperatura mínima de precalentamiento, las recomendaciones de Voestalpine para evitar riesgos de agrietamiento inducido por hidrógeno del riel grado R350HT, la cual es de $350^{\circ} \mathrm{C}$ según el texto "Welding recommendation for Vignol and Grooved rails" emitido por su Centro de Competencia en Soldadura ("Competence Center Welding") [14]. La Tabla 3 muestra los valores establecidos para las variables de soldeo que constituyen el WPS preliminar (pWPS). La metodología para la selección del material de aporte se presenta el numeral 3.1.

Tabla 3. Parámetros de soldeo del procedimiento preliminar (pWPS).

\begin{tabular}{|c|c|c|c|}
\hline PARÁMETRO & VALOR & PARÁMETRO & VALOR \\
\hline Proceso de soldeo & SMAW & Técnica & Arrastre \\
\hline Metal base & $\begin{array}{c}\text { Riel grado R350HT con perfil } \\
\text { 54E1 }\end{array}$ & $\begin{array}{c}\text { Nivel de hidrógeno del } \\
\text { electrodo }\end{array}$ & Extra bajo $=\mathrm{H} 3(<3 \mathrm{ml} / 100 \mathrm{~g})$ \\
\hline Materiales de aporte & DUR 300 DUR 350 & Corriente & $125-150 A$ \\
\hline Diámetro & $\varnothing 3.2 \mathrm{~mm}$ & Voltaje de arco & 21 a $23 V$ \\
\hline Longitud & $450 \mathrm{~mm}$ & Oscilación & 2 a $3 \mathrm{~mm}$ \\
\hline Posición & Plana (1C) & Velocidad de aplicación & 5 a $7 \mathrm{ipm}(2-3 \mathrm{~mm} / \mathrm{s})$ \\
\hline $\begin{array}{c}\text { Temperatura de } \\
\text { precalentamiento e inter-pases }\end{array}$ & $350^{\circ} \mathrm{C}$ & Ángulos del electrodo & Trabajo: $90^{\circ}$ Avance: $10-20^{\circ}$ \\
\hline Tipo de corriente y polaridad & DCEP & & \\
\hline
\end{tabular}




\section{PROCESO DE CALIFICACIÓN USANDO LA UNE-EN 15594}

Los ensayos de soldabilidad descritos en la norma UNE-EN 15594:2009 sirven como sistema de aprobación de consumibles y de procedimientos de soldeo para la reparación de rieles con procesos al arco eléctrico SMAW y FCAW [11, p. 7]. Esta norma determina tres tipos de soldaduras de prueba: (1) de cordón único que tiene el propósito de verificar la compatibilidad del aporte con el riel y la existencia de grietas en la soldadura después del pulido; (2) de capa única para establecer el efecto de la dilución y comprobar la integridad del depósito; y (3) de cinco capas o multicapas para determinar el comportamiento y la integridad del metal fundido sobre capas previas de metal fundido. Los detalles de estas pruebas se describen en los numerales 3.2.1, 3.2.2 y 3.2.3.

\subsection{Selección de los materiales de aporte}

La selección de los materiales de aporte se basó en que las soldaduras quedaran casi con las mismas propiedades mecánicas y metalúrgicas del riel grado R350HT. Para las propiedades mecánicas se utilizó el criterio de resistencia equivalente que consiste en que el metal base y de aporte tengan una resistencia a la tracción similar [15]. También se revisaron las sugerencias de materiales de aporte de las normas de consumibles UNE-EN 14700:2014 [16] y AWS A5.13:2000 [17] y las recomendaciones del fabricante de los rieles Voestalpine incluidas en sus textos técnicos [14]. A continuación, se resumen los criterios y metodología de selección de los electrodos de este estudio.

\subsubsection{Criterios de resistencia equivalente y de dureza}

Las normas UNE-EN 14700:2014 y AWS A5.13:2000 incluyen requisitos para múltiples clases de electrodos aplicables para el empleo en recargues superficiales duros, pero ninguna de ellas especifica concretamente la resistencia a la tracción de los metales fundidos sin dilución. Por tal motivo, se tomó como punto de partida la resistencia mínima a la tracción del riel R350HT de la norma UNE-EN 13674-1:2012 dada en la Tabla 1 (1175 MPa o 170000 psi) para correlacionar este valor con la dureza a través de la siguiente fórmula que se es bastante precisa para este tipo de aceros:

$$
\sigma_{u}=500^{*} H B N
$$

En la que $\sigma_{U}$ es la resistencia a la tracción del acero en $\mathrm{lb} / \mathrm{in}^{2}$ (psi) y HBN es su dureza en escala Brinell. Para obtener una soldadura con una resistencia a la tracción equivalente a la del riel R350HT se requiere, por tanto, usar un material de aporte con una dureza calculada de 340 HBN muy similar a la del riel. En cuanto a la microestructura ligada a las propiedades mecánicas, la idea fue tener un aporte ferrítico-martensítico con buenas resistencias al desgaste por fricción y al impacto requeridas para un adecuado desempeño en servicio.

\subsubsection{Recomendaciones de las normas UNE-EN 14700:2014 y AWS A5.13}

La norma UNE-EN 14700:2014 presenta ejemplos con las aplicaciones de los diferentes materiales de aporte en la Tabla A-4 de su Anexo A. En la Tabla 4 se muestra un fragmento de la Tabla A-4 dónde se recomiendan los consumibles con símbolo de aleación Fe1, Fe9 y Fe10 para componentes como rieles de ferrocarril que pueden tener desgaste por rodadura y por fricción por el contacto rueda-riel. Por su parte la AWS A5.13 indica en su numeral A7 que los electrodos clase EFe1 y EFe2 tienen suficientes elementos de aleación como desarrollar altas durezas sin necesidad de tratamiento térmico y resultan adecuados para contactos de rodadura metal-metal y contacto deslizante.

La Tabla 5 muestra los intervalos de composición química de los consumibles Fe1, Fe9 y Fe10 de la norma UNE-EN 14700 y los EFe1 y EFe2 de la AWS A5.13. Por los elementos de aleación se puede decir que el depósito sin dilución del Fe10 sería un acero inoxidable austenítico y que la aleación Fe9 es un acero al Manganeso que también puede producir microestructuras austeníticas, por lo que ambos se descartaron como posibles aportes para el riel R350HT. Los demás electrodos si pueden producir microestructuras ferrítico-martensíticas.

Tabla 4. Consumibles recomendados por la norma UNE-EN 14700 para contacto metal-metal.

\begin{tabular}{cccc} 
ESTRUCTURA DEL SISTEMA & TIPO DE DESGASTE & $\begin{array}{c}\text { EJEMPLOS DE } \\
\text { COMPONENTES }\end{array}$ & $\begin{array}{c}\text { SÍMBOLO DE } \\
\text { ALEACIÓN }\end{array}$ \\
Fe1 & Fesgaste por rodadura \\
Desgaste por fricción & Rieles de ferrocarril & Fe10 \\
\hline
\end{tabular}


Tabla 5. Valores de composición química de los depósitos sin dilución obtenibles con los consumibles para aplicaciones ferroviarias según las normas UNE-EN 14700 y AWS A5.13.

\begin{tabular}{|c|c|c|c|c|c|c|c|c|c|c|}
\hline NORMA & CLASE & $\% \mathrm{C}$ & $\% \mathrm{Mn}$ & $\% \mathrm{Si}$ & $\% \mathrm{Cr}$ & $\% \mathrm{Ni}$ & \%Mo & $\% W$ & $\% \mathrm{~V}$ & $\% \mathrm{Nb}$ \\
\hline \multirow{3}{*}{$\begin{array}{c}\text { UNE-EN } \\
\text { 14700:2014 }\end{array}$} & Fe1 & $\leq 0.4$ & $\leq 4.5$ & --- & $\leq 3.5$ & $\leq 3$ & $\leq 1$ & $\leq 1$ & $\leq 1$ & --- \\
\hline & $\mathrm{Fe} 9$ & $\leq 1.2$ & 9 a 20 & --- & $\leq 20$ & $\leq 5$ & $\leq 2$ & --- & $\leq 1$ & --- \\
\hline & Fe10 & $\leq 0.25$ & 3 a 8 & --- & 17 a 22 & 7 a 11 & $\leq 1.5$ & --- & - & $\leq 1.5$ \\
\hline \multirow{2}{*}{ AWS A5.13:2000 } & EFe1 & $0.04-0.20$ & $0.5-2.0$ & $\leq 1$ & $0.5-3.5$ & ---- & 1.5 & --- & --- & --- \\
\hline & Efe2 & $0.10-0.30$ & $0.5-2.0$ & $\leq 1$ & $1.8-3.8$ & 1.0 & 1.0 & --- & 0.35 & --- \\
\hline
\end{tabular}

Si bien no es posible afirmar que las dos normas UNE-EN y AWS sean equivalentes, resulta correcto decir que sugieren electrodos de características "comparables" debido a sus similitudes en composición química, propiedades y aplicaciones, exceptuando los aportes Fe9 y Fe10. La búsqueda de electrodos de consecución comercial se basó en los consumibles antes citados con preferencia en aquellos cubiertos por las normas europeas.

\subsubsection{Recomendaciones del Grupo VOESTALPINE}

Los rieles con perfil 54E1 grado R350HT usados en el estudio son producidos por ArcelorMittal del grupo VOESTALPINE. Para hacer reparaciones de la cabeza de rieles grado R350HT, el fabricante recomienda usar el electrodo UTP DUR 350 que es una referencia de la casa Voestalpine Böhler Welding que cumple con la norma DIN 8555 Clase E1UM-350 y la UNE-EN 14700 Clase EFe1 y que, en estado "as weld" no diluido, alcanza una dureza cercana a los 350 HBN tal como se describirá posteriormente. Por otro lado, el electrodo UTP DUR 300 cumple con las normas DIN 8555 Clase E 1-UM-300 y la UNE-EN 14700 Clase EFe1. La dureza del depósito de soldadura no diluido es de aproximadamente $300 \mathrm{HB}$ y la dureza de una capa de metal de aporte aplicada sobre un acero de $0.5 \%$ de carbono es aproximadamente $350 \mathrm{HB}$. Debido a que el riel grado $\mathrm{R} 350 \mathrm{HT}$ tiene un contenido de carbono aproximado de $0.8 \%$, este electrodo podría servir para reparaciones de campo de una sola capa que alcance durezas similares a las del riel y, por este motivo, se incluyó en el estudio.

\subsection{Etapas del proceso de aprobación de consumibles y del pWPS}

En esta sección se describen los detalles de las pruebas de aprobación de cordón único, capa única y multicapas para los electrodos seleccionados. En la Tabla 6 se resumen los datos de entrada de calor de las soldaduras de prueba calculados a partir de los registros de voltaje, corriente y velocidad de soldeo de cada tipo de prueba realizada.

Tabla 6. Entradas de calor calculadas a partir de los registros de soldadura de los cupones.

\begin{tabular}{cccccc}
\hline & \multicolumn{2}{c}{ DUR $\mathbf{3 5 0}$} & & \multicolumn{2}{c}{ DUR 300 } \\
\cline { 5 - 6 } \cline { 5 - 6 } Cupón de prueba & Entrada de calor [kJ/in] & Desv. Estándar [kJ/in] & & Entrada de calor [kJ/in] & Desv. Estándar [kJ/in] \\
Cordón único & 33,0 & No aplica & & 38,5 & No aplica \\
Capa única & 26,8 & 2,3 & 30,7 & 2,6 \\
Multicapa & 31,0 & 1,8 & No realizada & No realizada \\
\hline
\end{tabular}

\subsubsection{Ensayos de cordón único}

Esta prueba consiste en la aplicación de un cordón de soldadura con una longitud igual a la obtenible con el electrodo de $\mathrm{L}=450 \mathrm{~mm}$ sobre un cupón de prueba de riel y realizar una serie de ensayos. El cupón de prueba fue un riel con perfil $54 \mathrm{E} 1$ grado R350 HT con una longitud de $600 \mathrm{~mm}$. La cabeza se deja intacta, pero se pulió ligeramente para remover óxidos y suciedad. Posteriormente, se precalentó el riel a un mínimo de $350^{\circ} \mathrm{C}$ y se controló la temperatura en dos localizaciones que se ilustran en la Figura 3A: un punto A ubicado a $75 \mathrm{~mm}$ del inicio de la soldadura y un punto B localizado en la unión entre la cabeza y el alma del riel. Después se aplicó el cordón sobre el centro de la cabeza del riel siguiendo el pWPS. Se registraron los datos de temperatura entre pases, velocidad de aplicación del cordón, voltaje y amperaje para el registro de calificación de procedimiento o PQR. Una vez aplicado el cordón, se removió la escoria y las salpicaduras para hacer la inspección visual de apariencia, dimensiones y sanidad. Finalmente, se cortó una sección transversal sobre la cabeza del riel para evaluar la dilución, la sanidad del cordón y la microestructura. 


\subsubsection{Ensayos de capa única}

El cupón de prueba para el ensayo de capa única fue un tramo de riel de perfil 54E1 grado R350HT con una longitud de 600 mm. Al cupón se le mecanizó una cavidad o ranura con las dimensiones mostradas en las Figuras 3 A y B. La profundidad $D=2 \mathrm{~mm}$ fue tal que la superficie de la capa única quedara casi a ras de la superficie del riel. La longitud $L$ es la longitud de depósito obtenible con el electrodo (que para ambos electrodos fue de $\sim 280 \mathrm{~mm}$ ) menos $80 \mathrm{~mm}$, lo cual dió una longitud de rebaje de $200 \mathrm{~mm}$. Se tomó $\mathrm{S}=15 \mathrm{~mm}$ (mayor que 5D), quedando un valor de $\mathrm{L}+2 \mathrm{~S}$ igual a $230 \mathrm{~mm}$. El mecanizado de la ranura del cupón se hizo en una fresadora CNC tratando de que abarcara todo lo ancho de la cabeza del riel. Las dimensiones de la ranura se resumen en la Figura 3B. Las soldaduras fueron depositadas con un traslape del $50 \%$ entre los cordones adyacentes.

Debido a que el electrodo clase E11018-G se emplea comúnmente para realizar este tipo de reparaciones en campo, se realizó un ensayo de capa única con electrodo E11018-G con el fin de medir su dureza superficial y establecer su conveniencia para la reparación de defectos en cabezas de rieles grado R350HT. Se empleó un electrodo marca LINCOLN, referencia GRIDUCT 20 , clasificación E11018-G y diámetro $\varnothing 5 / 32$. Se realizaron las pruebas de capa única ya que ésta sería la condición en la que este electrodo podría dar su mayor dureza: si en una capa no logra la dureza mínima requerida para el riel, en múltiples capas los depósitos serían aún más blandos.

Una vez aplicados los depósitos de la capa única completa (Figura 3C) se removieron secciones transversales y longitudinales de los depósitos tal como lo especifica la norma UNE-EN 15594:2009 y que se muestran de forma esquemática en la Figura 3D. Estas secciones se analizaron mediante diversos ensayos de laboratorio y se evaluaron de acuerdo con los respectivos criterios de aceptación de la norma.

\subsubsection{Ensayos multicapas}

El cupón de prueba fue un tramo de riel grado R350HT con perfil $54 \mathrm{E} 1 \mathrm{de} 600 \mathrm{~mm}$ tal como se muestra en las Figuras $3 \mathrm{~A}$ y B. Las dimensiones del cupón se muestran en la Figura 3B. La cavidad o ranura tiene las siguientes dimensiones: (1) la profundidad $\mathrm{D}=10 \mathrm{~mm}$ para que la superficie de la última de las cinco capas de soldadura quede casi a ras de la superficie del riel; (2) la longitud del declive S=50 mm es igual a 5D; (3) la longitud del fondo L=100 mm; (4) la longitud total de la preparación $\mathrm{L}+2 \mathrm{~S}=200 \mathrm{~mm}$ para que sea $\geq 200 \mathrm{~mm}$ e igual a la longitud obtenible con el electrodo ( $280 \mathrm{~mm}$ ) menos $80 \mathrm{~mm}$. El traslape de los cordones depositados fue del $50 \%$. Se cortaron secciones transversales y longitudinales al inicio y final de los cordones como se muestra en la Figura 3D. Solo se realizaron las pruebas multicapa con el electrodo DUR350 ya que los otros dos no pasaron las pruebas de capa única.

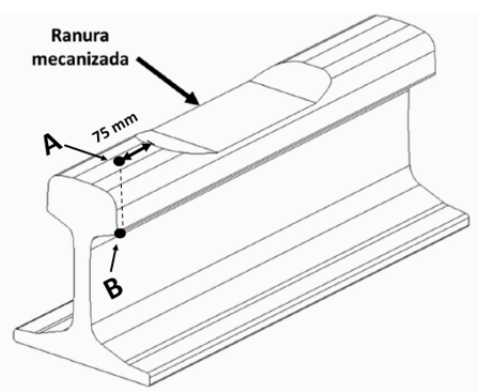

A. Esquema del cupón con ranura usado en las pruebas de capa única y multicapa.

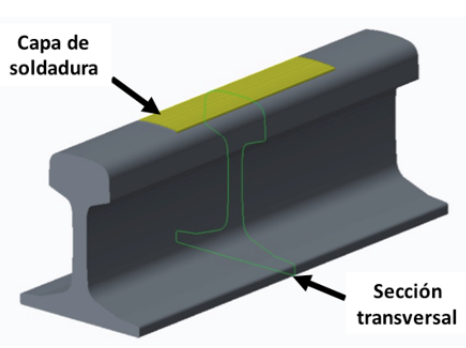

C. Esquema de aplicación de cordones de soldadura en capa única y multicapa.
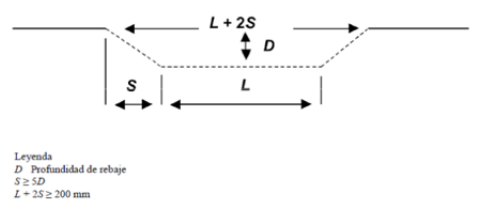

Capa única: S: $15 \mathrm{~mm}, \mathrm{~L}: 200 \mathrm{~mm}, \mathrm{D}: 2 \mathrm{~mm}$ Multicapas: S: $50 \mathrm{~mm}, \mathrm{~L}: 100 \mathrm{~mm}, \mathrm{D}: 10 \mathrm{~mm}$ $\mathrm{L} 1=10, \mathrm{~A}=20 \mathrm{~mm}$ (ver figura $3 \mathrm{C}$ ) $\mathrm{D}=$ Profundidad rebaje $=10 \mathrm{~mm}$

B. Dimensiones de las ranuras de una capa y multicapas según la norma UNE-EN 15594.

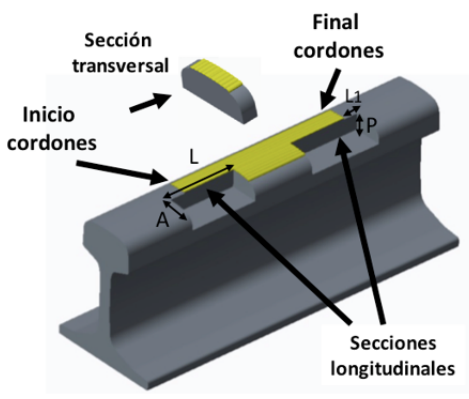

D. Extracción de las secciones longitudinales y trasversal en cupón de capa única y multicapas.

Figura 3. Esquemas de los cupones de prueba, dimensiones de las ranuras, aplicación de capas y extracción de secciones de interés de acuerdo con la norma UNE-EN 15594:2009 [11]. 


\section{RESULTADOS Y DISCUSIÓN}

\subsection{Caracterización de electrodos}

En la Tabla 7 se presentan el intervalo de contenido de elementos de aleación establecidos en la norma UNE-EN 14700:2014 para el electrodo Fe1, las composiciones químicas típicas de los depósitos sin dilución de los electrodos DUR 300 y DUR 350 emitidas por el fabricante Voestalpine Böhler Welding y los resultados de las pruebas de composición química obtenidos en depósitos sin dilución con ambos electrodos. El depósito del electrodo DUR 350 contiene una mayor cantidad de $\mathrm{Cr}, \mathrm{Mn}$ y Si que el depósito del DUR 300. Sin embargo, éste último presenta un contenido de carbono más alto a diferencia de lo que se esperaba para este electrodo de menor dureza.

Ambos electrodos cumplen los intervalos de composición química de la norma UNE-EN 14700:2014 y, aunque esta norma no especifica concretamente el contenido de silicio del Fe1, si afirma que debe estar presente en los depósitos ya que es un desoxidante muy común que ayuda cuando se hacen soldaduras sobre superficies contaminadas u oxidadas, lo cual es común en ferrovías. La AWS A5.13 indica un contenido de Si para el EFe1 es menor que el 1\% (Tabla 5). Los contenidos de Mn y Cr en los depósitos estudiados son similares a los contenidos típicos reportados por el fabricante. Sin embargo, es evidente la diferencia en el contenido de carbono para ambos electrodos en relación con el valor típico del productor, en especial para el DUR 300 en el que la diferencia es cercana al $0.1 \%$.

Tabla 7. Composición química de los electrodos DUR 300 y DUR 350 según: norma, catálogos y pruebas de depósitos sin diluir hechas en el estudio.

\begin{tabular}{|c|c|c|c|c|c|c|c|c|c|}
\hline \multirow{2}{*}{ MATERIAL } & \multicolumn{9}{|c|}{ COMPOSICIÓN QUÍMICA DEL DEPÓSITO (\% en peso) } \\
\hline & C & Si & $\mathrm{Cr}$ & $\mathbf{N i}$ & Mn & Mo & w & $\mathbf{v}$ & Otros \\
\hline UNE-EN 14700 Fe1 & $\leq 0.4$ & --- & $\leq 3.5$ & $\leq 3$ & $\leq 4.5$ & $\leq 1$ & $\leq 1$ & $\leq 1$ & \\
\hline Catálogo DUR 300 & 0.170 & 0.7 & 1.3 & --- & 1.2 & --- & --- & --- & \\
\hline Catálogo DUR 350 & 0.2 & 1.2 & 1.8 & --- & 1.4 & --- & --- & --- & \\
\hline UTP DUR 300 & 0.263 & 1.208 & 1.287 & 0.026 & 1.287 & 0.0083 & 0.0026 & 0.0074 & $\begin{array}{c}\text { P:0.013 } \\
\text { S: } 0.0075\end{array}$ \\
\hline UTP DUR 350 & 0.218 & 1.348 & 1.712 & 0.021 & 1.374 & 0.0064 & 0.0020 & 0.025 & $\begin{array}{l}\text { P:0.0093 } \\
\text { S: } 0.0071\end{array}$ \\
\hline
\end{tabular}

\subsection{Ensayos de cordón único}

La Figura 4 muestra los resultados de la inspección visual con la apariencia de los cordones y los resultados de los líquidos penetrantes después de amolar entre 0.5 y $0.8 \mathrm{~mm}$. Al final del cordón aplicado con electrodo DUR 300 se detectó una grieta de cráter ocasionada por el empleo de una técnica inadecuada de extinción del arco. De resto, las soldaduras quedaron libres de defectos y cumplieron los criterios de aceptación establecidos en el numeral 4.6.9.2 de la norma UNE-EN 15594:2009 y ambos electrodos se consideraron conformes para las pruebas de capa única.

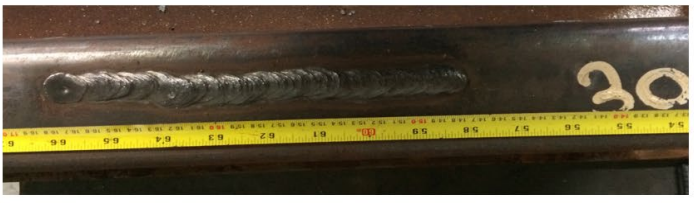

A. Apariencia del cordón único con DUR 300

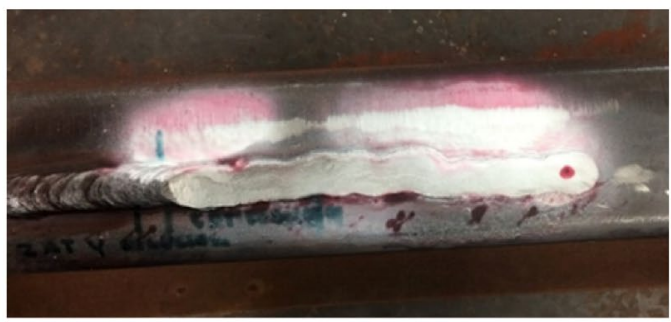

C. Líquidos penetrantes de cordón con DUR 300 .

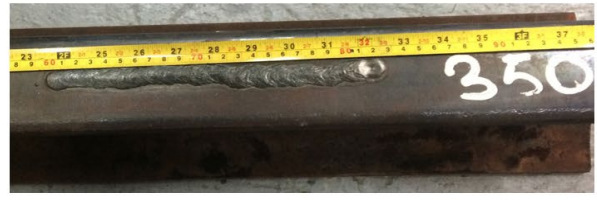

B. Apariencia del cordón único con DUR 350

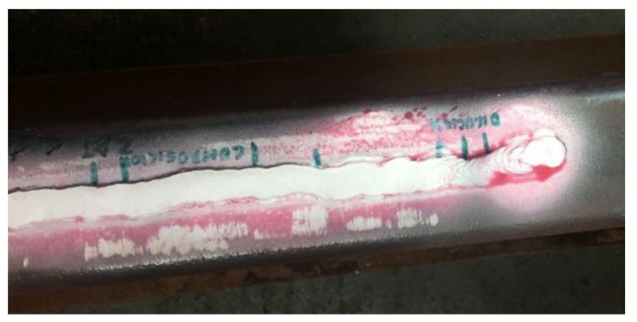

D. Líquidos penetrantes de cordón con DUR 350.

Figura 4. Resultados de la inspección visual y con líquidos penetrantes para cupones de cordón único. 
Los otros ensayos diferentes a los requeridos por la norma UNE-EN 15594:2009 se presentan en la Figura 5 que muestra el macroataque de la sección transversal de los cupones de prueba de cordón único para ambos electrodos. En la Tabla 8 se resumen las dimensiones y datos de las diversas regiones de la soldadura (metal fundido, zona afectada térmicamente -ZAT- y \% de dilución). Ambas soldaduras tienen una ZAT de forma circular típica de un flujo de calor tridimensional propio de placa gruesa no obstante la alta temperatura de precalentamiento de $350^{\circ} \mathrm{C}$. El cordón obtenido con electrodo DUR 300 es un poco más ancho que el obtenido con DUR 350 y presenta una ZAT de mayores dimensiones en diámetro y ancho. Los porcentajes de dilución de los cordones fueron de $35 \%$ para el electrodo DUR 300 y de $42 \%$ para el electrodo DUR 350.

Las microestructuras formadas en las regiones del material fundido y la zona afectada térmicamente del cordón único con ambos electrodos se muestran en los resultados de las pruebas de capa única debido a que resultaron muy similares a las obtenidas en las pruebas de cordón único. El metal fundido obtenido con DUR 300 presenta una dureza de 318-325 HV y la ZAT adyacente a la línea de fusión llega a 443-451 HV; luego la dureza se reduce hasta llegar a la del riel grado $350 \mathrm{HT}$ ( 370 HV). EI metal fundido obtenido con DUR 350 tiene una dureza de 418-429 HV y la ZAT adyacente a la línea de fusión está en 400-406 HV para reducirse hasta llegar a la dureza del riel grado $350 \mathrm{HT}$. En este caso se puede concluir que los dos electrodos cumplieron los requisitos de las pruebas de cordón único.

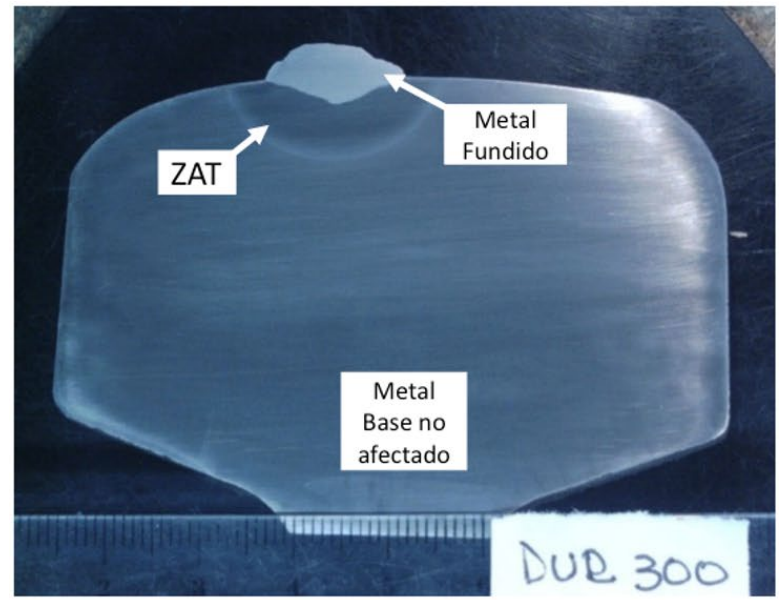

A. Cordón único con electrodo DUR 300.

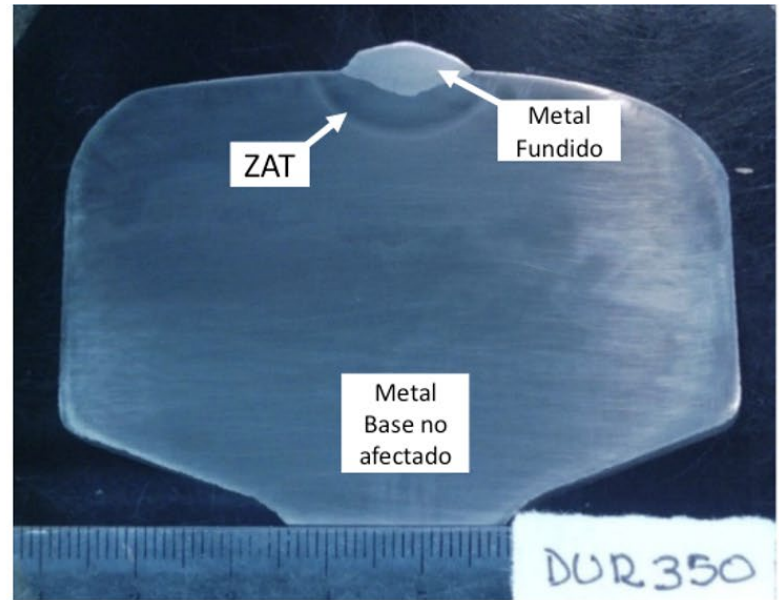

B. Cordón único de electrodo DUR 350

Figura 5. Imágenes de la sección transversal de los cupones de prueba con cordón único aplicados con electrodos DUR 300 y DUR 350 sobre riel con perfil 54E1 grado R350HT.

Tabla 8. Dilución y dimensiones de las regiones de las soldaduras de cordón único con DUR 300 y DUR 350.

\begin{tabular}{|c|c|c|c|c|c|c|c|}
\hline \multirow{2}{*}{$\begin{array}{l}\text { Cupón de } \\
\text { prueba }\end{array}$} & \multirow{2}{*}{$\begin{array}{c}\emptyset_{\mathrm{ZAT}} \\
(\mathrm{mm})\end{array}$} & \multirow{2}{*}{$\begin{array}{l}\text { Área de la } \\
\text { ZAT }\left(\mathrm{mm}^{2}\right)\end{array}$} & \multicolumn{2}{|c|}{ Ancho de la ZAT (mm) } & \multirow{2}{*}{$\begin{array}{c}\text { Ancho del } \\
\text { cordón (mm) }\end{array}$} & \multirow{2}{*}{$\begin{array}{l}\text { Área del metal } \\
\text { fundido }\left(\mathrm{mm}^{2}\right)\end{array}$} & \multirow{2}{*}{ Dilución (\%) } \\
\hline & & & Superficie & Sub-superficie & & & \\
\hline DUR 300 & $\sim 23$ & 125 & 3 a 4 & 5 a 6 & $\sim 15$ & 58 & $35.5 \%$ \\
\hline DUR 350 & $20-21$ & 86 & 2 a 3 & 3 a 4 & $\sim 13-14$ & $48-49$ & $42 \%$ \\
\hline
\end{tabular}

\subsection{Ensayos de capa única}

Las secciones transversales y longitudinales extraídas de los cupones de capa única para los electrodos DUR 300 y DUR 350 se muestran en la Figura 6. Los números en la Figura 6 A y B indican la secuencia de aplicación de los diez cordones que conforman las capas y las líneas punteadas demarcan las ZATs de cada cordón. La forma circular de las ZATs indica que el flujo de calor durante el soldeo fue tridimensional. Las Figuras 6C y D muestran el inicio y final de los cordones obtenidos con DUR 300, y las Figuras 6 E y $\mathrm{F}$ muestran el inicio y final de los cordones aplicados con DUR 350. No se detectaron defectos como grietas o faltas fusión entre los metales fundidos y el metal base ni entre los cordones que conforman cada capa. 


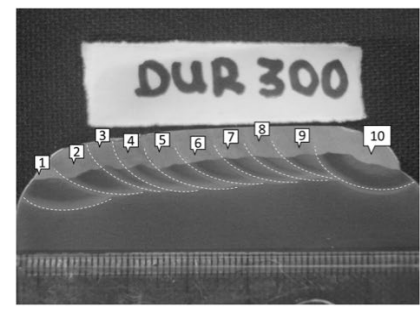

A. Capa única con DUR 300.

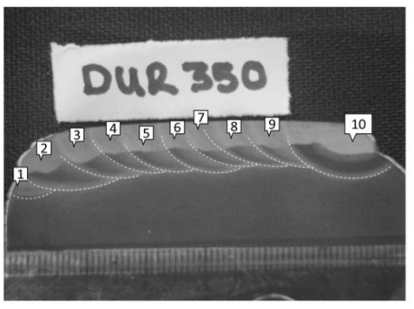

B. Capa única con DUR 350

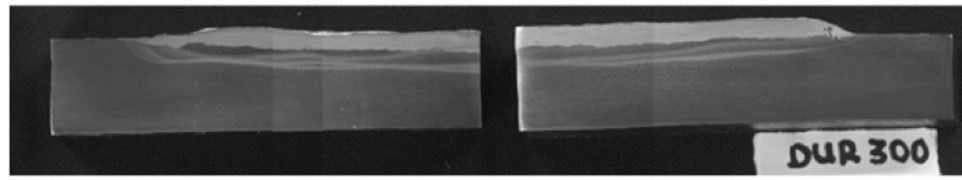

C. Sección longitudinal: Final de la capa

D. Sección longitudinal: Inicio de la capa

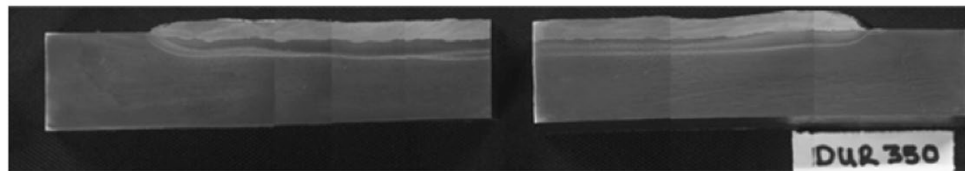

E. Sección longitudinal: Final de la capa

F. Sección longitudinal: Inicio de la capa

Figura 6. Imágenes de las secciones transversales y longitudinales de capa única. Secciones transversales: (A) DUR 300 y (B) DUR 350. Secciones longitudinales: (C y D) DUR 300 y (E y F) DUR 350.

Las microestructuras resultantes en los ensayos de capa única con los materiales de aporte DUR 300 y DUR 350 son muy similares por lo que solo se presentarán las del electrodo DUR 350. En la Figura 7, se aprecian las micrografías representativas de cada región de la soldadura aplicada con el electrodo DUR 350. El metal fundido mostrado en la Figura 7 A exhibe una microestructura compuesta de bainita más martensita en forma de dendritas. La Figura 7B, muestra el traslape de dos cordones y la línea de fusión. La ZAT se observa en la Figura 7C y está compuesta de perlita fina y puede contener porcentajes muy bajos de bainita y martensita que no son diferenciables con las técnicas usadas en este artículo. La Figura 7D corresponde a la microestructura del metal base no afectado por el calor que consiste fundamentalmente de perlita fina.

Las medidas de dureza fueron realizadas en las secciones transversales y en la superficie de los cupones de capa única. La ZAT y el metal fundido tienen una dureza de $412 \mathrm{HV}$ y $402 \mathrm{HV}$ para el DUR 350 y de $345 \mathrm{HV}$ y $337 \mathrm{HV}$ para el electrodo DUR 300 en el cordón número cuatro. Los cordones número diez presentan una dureza de $424 \mathrm{HV}$ en el electrodo DUR 350 . Mientras tanto, el electrodo DUR 300 en su cordón número diez tiene una dureza de 345 HV en el metal fundido y de 372 HV en la ZAT. Las mediciones de dureza en el cordón cuatro a comparación con las tomadas en el cordón diez son más bajas debido a los ciclos térmicos subsecuentes ocasionados por los demás cordones de la capa única.

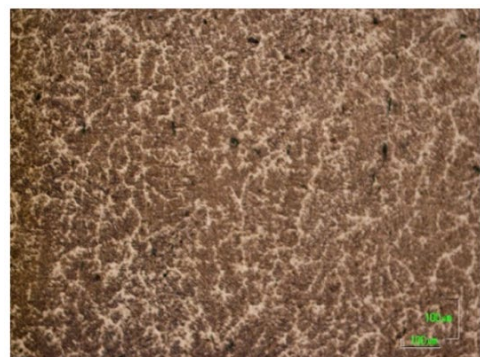

A. Metal fundido (zona de fusión)

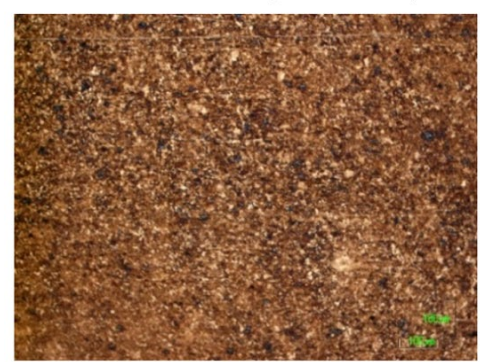

C. Zona afectada térmicamente (ZAT)

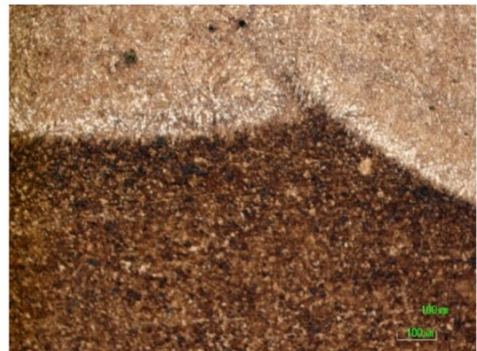

B. Metal fundido, línea de fusión y ZAT

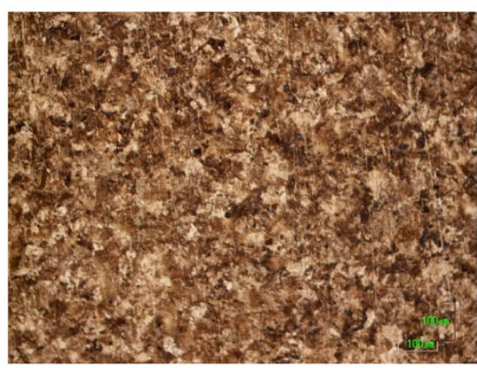

D. Metal base no afectado

Figura 7. Microestructuras de la capa única aplicada con electrodo DUR 350 (Tomadas a 100X): (A) Metal fundido, (B) Metal fundido, línea de fusión y ZAT (C) ZAT y (D) Metal base. 
Las durezas del depósito con electrodo DUR 350 dieron entre 402 y 424 HV y están muy cercanas al límite superior de dureza del riel grado R350HT que, de acuerdo con la norma UNE-EN 13674-1, debe estar entre 350 y 390 HB (370-412 HV). Por otro lado, la norma UNE-EN 15594:2009 establece que la capa única sobre este grado de riel no debe sobrepasar los 400 HBW $(423 \mathrm{HV})$. Las durezas medidas en el metal fundido y la ZAT del cordón 10 fueron de 424 HV, lo cual no se considera una variación significativa respecto al valor superior de la norma. Los valores de dureza de los metales fundidos del DUR 300 fueron de $337-$ $345 \mathrm{HV}$ que resultan muy por debajo del mínimo nivel de dureza del riel grado R350HT que es de 370-412 HV, por lo que se consideran inaceptables.

Las durezas superficiales tomadas sobre los cupones de capa única obtenidos con los diferentes materiales de aporte indican que la dureza promedio de la capa de DUR 300 es de $351 \pm 11$, la cual está por debajo de la mínima dureza del riel R350HT de 370 HV dada en la norma UNE-EN 13674. Por otro lado, la dureza promedio de la capa de DUR 350 es de $417 \pm 10$ que no supera la máxima dureza de 423 HV permitida por la norma UNE-EN 15594. Por este motivo, el electrodo DUR 300 no puede ser aprobado para reparaciones de superficies de rodadura de ferrovías de acero grado R350HT, contrario a lo que se infería a partir de la información del fabricante de que las durezas de los depósitos de una capa sobre materiales con altos porcentajes de carbono alcanzarían durezas del orden de $350 \mathrm{HB}$.

Por último, se hicieron pruebas de capa única aplicadas con un aporte E11018 con el fin de comprobar su idoneidad por ser de uso común por algunos administradores ferroviarios para reparaciones de campo. La dureza promedio sobre el depósito de capa única aplicada con electrodo E11018 fue de $334 \pm 15$ HV que está por muy por debajo del mínimo de 370 HV establecido por la norma UNE-EN 13674-1:2012 para la superficie de un riel R350HT. Ni el electrodo DUR 300 ni el E11018 cumplen los requisitos establecidos por la norma UNE-EN 15594:2009 para las pruebas de capa única y se descartaron sin hacerles las pruebas multicapas.

\subsection{Ensayos multicapa}

En la Figura 8 se observa el macroataque de la sección trasversal y el macroataque de las dos secciones longitudinales (inicios y finales) del cupón de multicapa aplicado con material de aporte DUR 350. No se detectaron defectos como grietas, poros o faltas fusión entre el metal fundido y el metal base ni entre los 37 cordones que conforman las cinco capas de prueba. Puede notarse en las macroataque de las probetas longitudinales que no se presentaron poros en los inicios o terminaciones de los cordones.

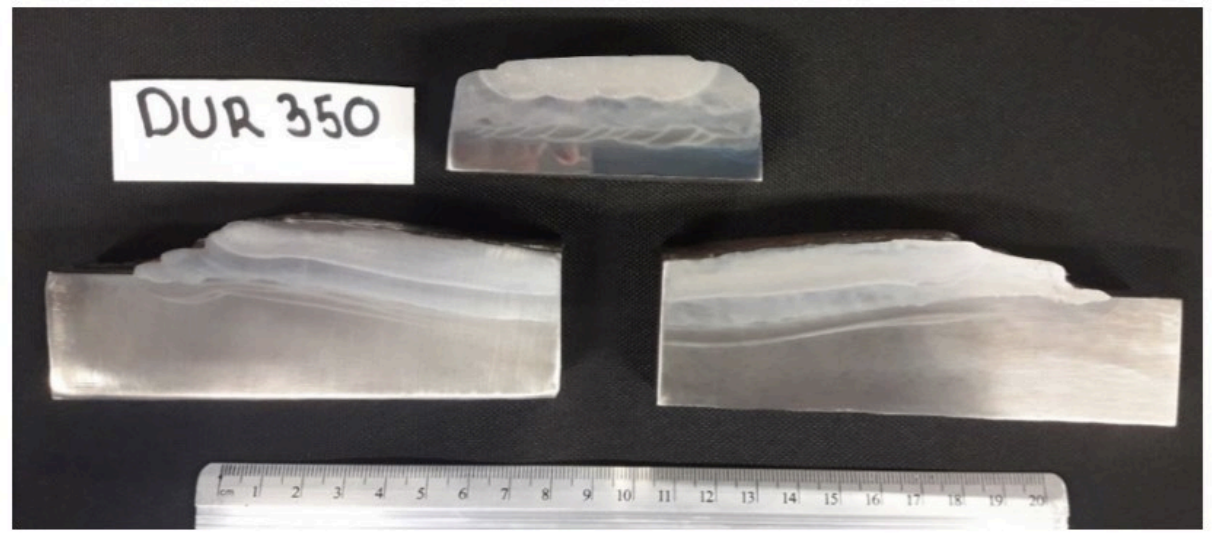

Figura 8. Imagen de las probetas extraídas del cupón de capa múltiple con electrodo DUR 350. Arriba: Sección transversal. Abajo: Secciones longitudinales

Se hizo un barrido de durezas sub-superficial siguiendo la norma UNE-EN 15594 con la primera huella a $3 \mathrm{~mm}$ de la superficie y, luego, tomando datos cada $1.5 \mathrm{~mm}$ hasta cubrir toda la sección transversal. La Figura 9 muestra el perfil de dureza del depósito. Las mayores durezas están en las últimas tres capas con valores de $400 \mathrm{HV}$ que alcanzan un espesor aproximado de $10 \mathrm{~mm}$. Debajo de las tres capas más superficiales (capas 3, 4 y 5) la dureza tiene valores muy bajos de 319 HV; estas capas (1 y 2) y la ZAT experimentaron más de tres ciclos térmicos, lo que puede explicar su baja dureza. Además, está región es muy profunda en la cabeza del riel dónde la velocidad de enfriamiento durante el soldeo se puede reducir hasta valores que produzcan estas durezas tan bajas. La dureza de la ZAT recupera el valor nominal del riel R350HT que es de $370 \mathrm{HV}$. La dureza sub-superficial en los primeros $10 \mathrm{~mm}$ fue de $396 \pm 9 \mathrm{HV}$ que está en el rango admisible por la norma de 358-412 HV. Sin embargo, para más de cuatro capas la dureza sub-superficial de la primera capa y la ZAT cae por debajo de la del riel R350HT. De acuerdo con lo anterior, la dureza de los depósitos en zonas con profundidad mayor a $10 \mathrm{~mm}$ no cumpliría los requerimientos de la norma en términos de dureza. En consecuencia, el electrodo DUR 350 serviría para hacer recargues menores o iguales que $10 \mathrm{~mm}$ (aproximadamente tres capas), lo cual resultaría suficiente para reparaciones de superficies de rodadura en ferrovías. 
Por otro lado, un asunto inquietante de la norma UNE-EN 15594-1:2009 es que exige pruebas en soldaduras superficiales de mínimo cinco (5) capas lo cual resulta inusual en las reparaciones ordinarias de ferrovías que son del orden de unos cuantos milímetros. Un aporte interesante del estudio es que no fue posible cumplir a cabalidad los criterios de la norma ya que la acumulación progresiva de cinco capas (y por ende los múltiples ciclos térmicos de los cordones de soldadura que las componen) hacen que las capas iniciales se reblandezcan y que no sea factible obtener una dureza homogénea en todo el espesor. No resultó factible cumplir de manera absoluta los requisitos de la norma y parece haber una brecha con la magnitud de las reparaciones de campo en la recuperación de ferrovías.

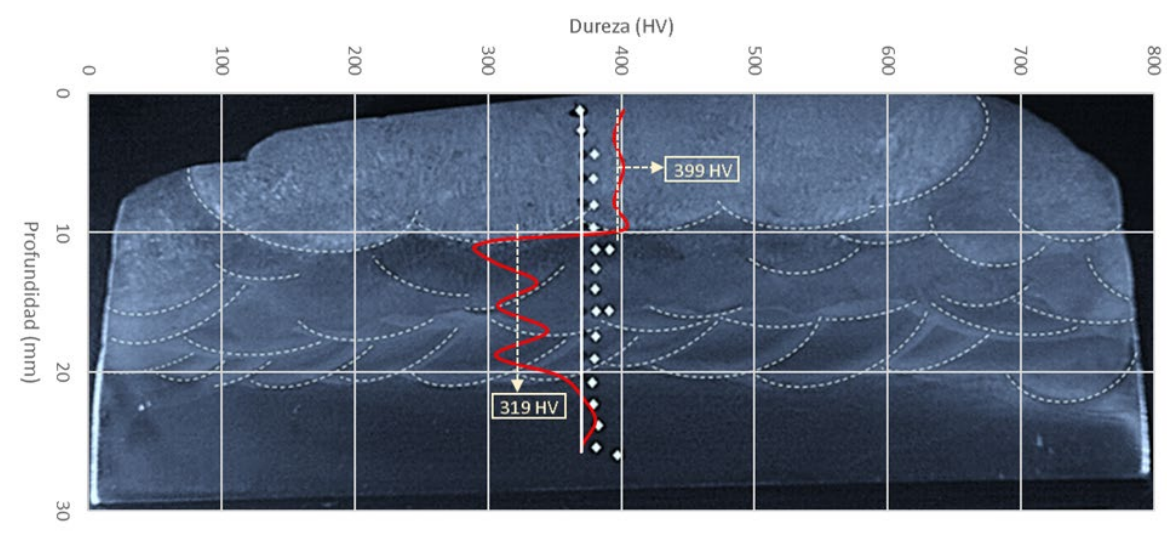

Figura 9. Perfil de dureza del depósito de múltiples capas aplicadas con DUR 350

Adicionalmente, se tomaron durezas en la superficie de la última capa sobre los cordones 1, 4 y entre la línea de fusión de los cordones 2 y 3 para el cupón de multicapa. Los valores de dureza obtenidos en la superficie multicapa con DUR 350 alcanzaron valores promedio de $396 \pm 9$ HV que está en el intervalo de 358-412 HV de la norma.

La Figura 10 muestra la microestructura del depósito de múltiples capas aplicadas con electrodo DUR 350 para la capa 5 (Figura 10A), la capa 3 (Figura 10B). Los principales cambios observados en las microestructuras están relacionados con la desaparición de la morfología de listones observados en la capa 5. En este caso los listones sufren un revenido por los cordones aplicados posteriormente para el caso de la capa 3. La sucesión de ciclos térmicos genera un movimiento de defectos y de carbono que resulta en una disminución de dureza. Con estas imágenes en microscopía óptica no fue posible evaluar la microestructura de forma detallada así que se realizaron pruebas en microscopio electrónico de barrido.

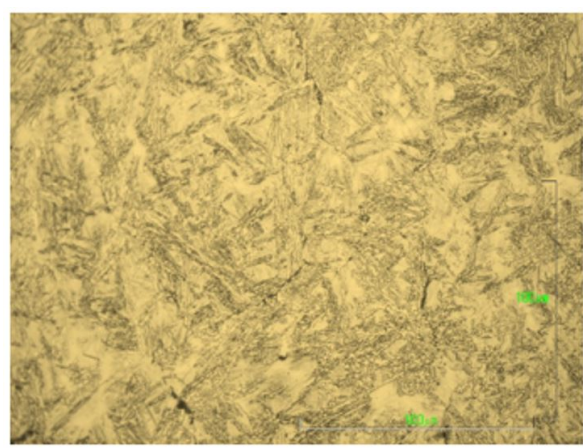

(A) Metal fundido de capa 5 a 50X.

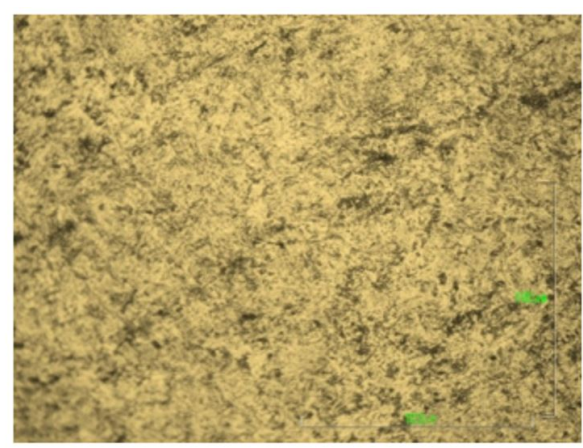

(B) Metal fundido de capa 3 a 50X.

Figura 10. Microestructuras del depósito de múltiples capas aplicadas con electrodo DUR 350. (A) Capa 5; (B) Capa 3.

La Figura 11 muestra la microestructura en tres regiones representativas de la muestra de soldadura multicapa observada en microscopio electrónico de barrido de emisión de campo. Las Figuras 11A y B muestran la microestructura en la región de alta dureza de los cordones superficiales (capa 5). En esta zona la microestructura consiste de bainita con algunos porcentajes de martensita. La proporción de estas fases no es identificable con las técnicas usadas en este estudio. Se puede observar la presencia de carburos bainíticos con un aspecto poco definido en términos de ángulos y distinto al observado en aceros bainíticos por la formación desde una estructura de solidificación por soldadura. La dureza de esta zona y la microestructura coincide con algunos reportes encontrados en la literatura para el mismo material [18]. La microestructura es compleja y dada la composición química de esta aleación no existen disponibles herramientas de predicción tales como diagramas CCT. 
Las Figuras 11C y D muestran la microestructura en la región con dureza de 319 HV (Capa 3). En esta zona se observa una microestructura que consiste en una matriz de ferrita con carburos esferoidizados. En algunas zonas (ver flechas en Figura 11D) se observa el inicio de la formación de perlita. En esta región la martensita, bainita y carburos se han revenido como consecuencia de los múltiples cordones de soldadura que generaron varios ciclos térmicos. En la ZAT del material base (ver Figuras $11 \mathrm{E}$ y F) se observa de nuevo la perlita fina acompañada de perlita gruesa.

Para el caso de la ZAT del material base y con el fin de sustentar la presencia de esta microestructura se realizaron unos cálculos a partir de los parámetros de soldeo y de las características del riel (propiedades térmicas y dimensiones). Con esto datos se calculó el espesor relativo que dio un valor de 1.4 indicando que se trata de un caso de placa gruesa o flujo tridimensional tal como se observa en las figuras del macroataque de cordón único. Para las condiciones de flujo tridimensional se calculó el tiempo de enfriamiento entre 800 y $500^{\circ} \mathrm{C}$ con la fórmula reportada en la literatura [19]. Se obtuvo un valor de $\Delta \mathrm{t} 8 / 5$ de aproximadamente 19.3 segundos. Se observa que los tiempos de enfriamiento coinciden con los valores mínimos de $\Delta \mathrm{t} 8-5$ (mayores a $20 \mathrm{~s}$ ) recomendados en la literatura técnica para materiales de rieles con una temperatura de precalentamiento entre 200 y $300^{\circ} \mathrm{C}[20]$.

Con los datos anteriores se trazó una curva de enfriamiento respectiva sobre el diagrama CCT del acero de rieles R260 (no mostrado) que posee una composición química similar a la del riel R350 HT. La predicción de la dureza con dicho diagrama es muy similar a las medidas en el estudio. Para los valores de dureza en la ZAT de $370 \mathrm{HV}$, la microestructura estaría formada principalmente de perlita con algún porcentaje bajo de bainita y martensita como se evidenció en la Figura 11 E y F.

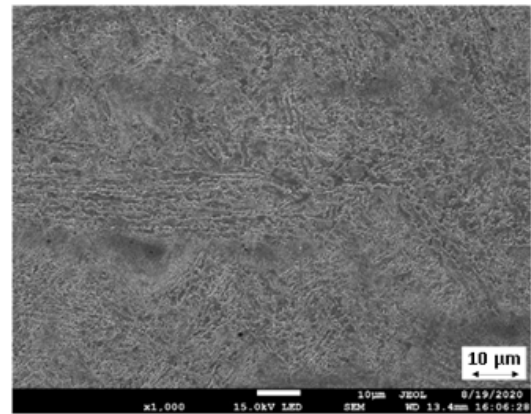

a) Capa 5 , a $2 \mathrm{~mm}$ del último cordón

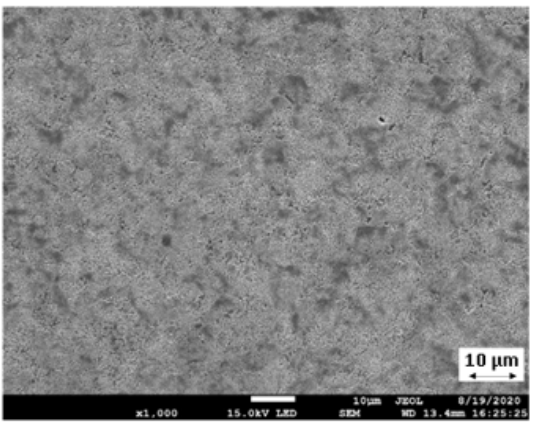

c) Capa 3, a $16 \mathrm{~mm}$ del último cordón, zona reblandecida

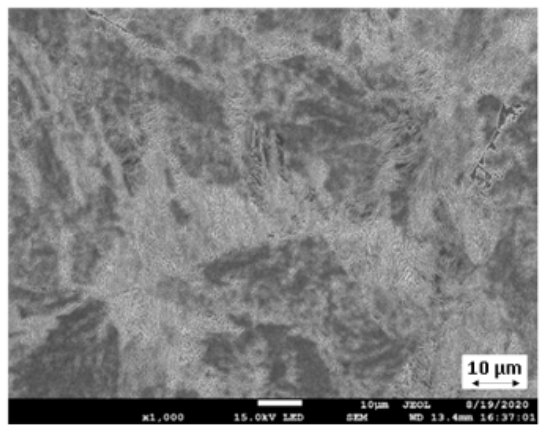

e) ZAT de metal base, $25 \mathrm{~mm}$ del último cordón

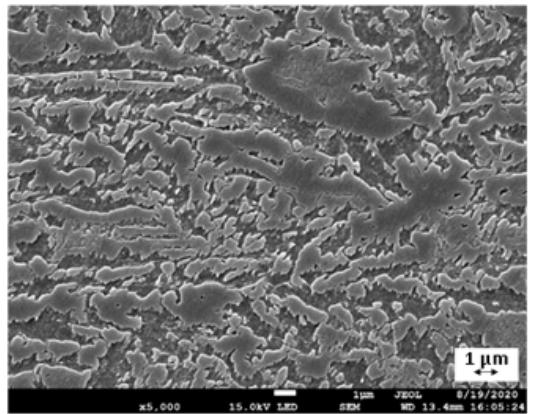

b) Detalle de capa 5, a $2 \mathrm{~mm}$ del último cordón

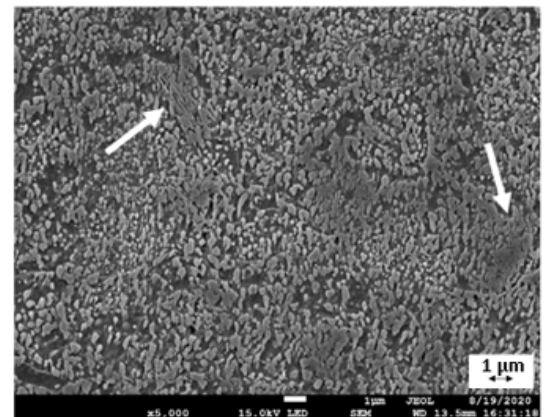

d) Detalle de capa 3, a $16 \mathrm{~mm}$ del último cordón, zona reblandecida

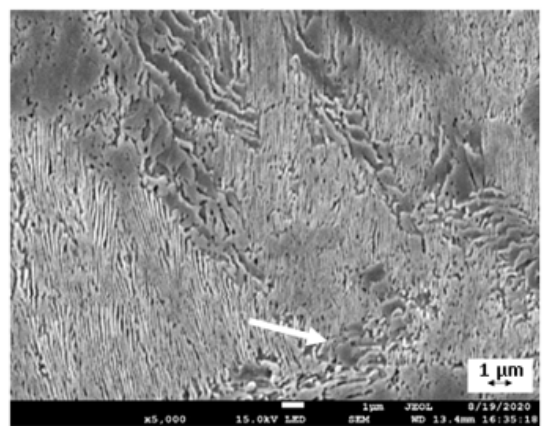

f) Detalle de ZAT, $25 \mathrm{~mm}$ del último cordón

Figura 11. Microestructuras del depósito de múltiples capas aplicadas con electrodo DUR 350 observadas con SEM. (a) Capa 5 a 1000X; (b) Capa 5 a 5000X; (c) Capa 3 a 1000X; (d) Capa 3 a 5000X; (e) ZAT a 1000X; (f) ZAT a 5000X. 


\subsection{Resumen de resultados y criterios de aceptación de los depósitos obtenidos}

En la Tabla 9 se resumen los valores de dureza obtenidos en: (1) las capas únicas con electrodos DUR 300, E11018-G y DUR 350 tanto en su superficie como por debajo de la superficie; (2) en la sub-superficie de las capas múltiples (cinco en total) y (3) en la superficie de las probetas de que corresponden a $100 \%$ material de aporte sin dilución. También se incluyen los criterios de aceptación de las normas.

El valor de dureza promedio para el consumible E11018 fue de $334 \pm 15$ HV y está por debajo del mínimo de 370 HV establecido por la norma UNE-EN 13674-1:2012 para la superficie de un riel R350HT. Por este motivo se considera que el electrodo E11018-G no es adecuado para las reparaciones con soldadura de rieles grado R350HT.

Se nota que las durezas superficiales de las capas únicas aplicadas con electrodos DUR 300 y E11018-G (351 \pm 11 y $334 \pm 15$, respectivamente) son inferiores a los 370HV establecidos en la norma UNE-EN 13674-1:2012. La dureza sin dilución del metal fundido con electrodo DUR 300 es todavía menor y llega a los $314 \pm 11$. La misma tendencia a reducir la dureza con el incremento en el número de capas sucederá con el E11018-G. El único electrodo que pasa los criterios de aceptación es el DUR 350 que presentó una dureza superficial de $417 \pm 10$ en una capa y de $370 \pm 20$ en multicapas, y una dureza sub-superficial de $396 \pm 9$ en las últimas capas, haciéndolo viable para reparaciones sobre rieles grado $350 \mathrm{HT}$ que no superen tres capas de soldadura o aproximadamente $10 \mathrm{~mm}$.

La norma UNE-EN-15594 presenta criterios de aceptación para las pruebas de cinco capas que son difíciles de cumplir dado que existe un efecto no predecible de los ciclos térmicos en la dureza de los depósitos aplicados previamente. En este caso, el electrodo DUR 350 cumpliría parcialmente la norma debido a este efecto de reblandecimiento.

Tabla 9. Consolidado de durezas obtenidas con electrodos DUR 300, E11018-G y DUR 350 incluyendo los criterios de aceptación de las normas UNE-EN 15594:2009 y 13674-1:2012. Los criterios subrayados y celdas en fondo gris indican el cumplimiento de criterios de la norma.

\begin{tabular}{|c|c|c|c|c|c|}
\hline \multirow{2}{*}{\multicolumn{2}{|c|}{ MATERIAL APORTE O NORMA-UBICACIÓN }} & \multicolumn{4}{|c|}{ DUREZA REQUERIDA POR NORMA UNE-EN(HV) } \\
\hline & & $\begin{array}{l}\text { UNA CAPA (Sub- } \\
\text { superficial) }\end{array}$ & $\begin{array}{l}\text { UNA CAPA } \\
\text { (Superficial) }\end{array}$ & $\begin{array}{l}\text { MULTICAPA (Sub- } \\
\text { Superficial) }\end{array}$ & $\begin{array}{r}\text { MULTICAPA EN } \\
\text { PROBETA DE CQ }\end{array}$ \\
\hline \multirow{5}{*}{$\begin{array}{c}\text { CRITERIOS UNE-EN- } \\
15594 \\
\text { UNE-EN } 13674- \\
1: 2012\end{array}$} & SUPERFICIAL & Max. 423 & Max. 423 & $358-412$ & Max. 423 \\
\hline & BAJO LA SUPERFICIE & NA & NA & MAX. 400 & NA \\
\hline & RIEL GRADO R350HT & \multicolumn{4}{|c|}{ 370-412 (350-390HBW) } \\
\hline & UTP DUR 300 & $337-345$ & $351 \pm 11$ & NA & $314 \pm 11$ \\
\hline & E11018-G & No se hizo & $334 \pm 15$ & No se hizo & No se hizo \\
\hline \multirow[t]{2}{*}{ ELECTRODO } & \multirow[b]{2}{*}{ UTP DUR 350} & \multirow[b]{2}{*}{$\underline{402-424}$} & \multirow[b]{2}{*}{$\underline{414 \pm 10}$} & $\frac{396 \pm 9 \text { En capas } 3,4}{\text { y } 5 \text { (Cumple la }}$ & \\
\hline & & & & $\begin{array}{c}\frac{\text { norma) }}{319 \text { HV en ZAT y en }} \\
\text { Capas } 1 \text { y } 2 \text { (No } \\
\text { cumple la norma) } \\
\end{array}$ & $\underline{370 \pm 20}$ \\
\hline
\end{tabular}

\section{CONCLUSIONES}

El electrodo DUR 300 no fue aprobado ni calificado como consumible para hacer reparaciones con soldadura de rieles grado R350HT ya que no cumple con los requisitos de capa única establecidos en las normas UNE-EN 13674-1:2012 y 15594:2009: su dureza superficial fue de $351 \pm 11$ y debió estar en el rango de 370-423 HV.

El electrodo E11018-G no queda ni aprobado ni calificado como consumible para hacer reparaciones con soldadura de rieles grado R350HT ya que no pasa los requisitos de capa única establecidos en las normas UNE-EN 13674-1:2012 y 15594:2009: su dureza superficial fue de $334 \pm 15$ y debió estar en el rango de 370-423 HV.

El electrodo DUR 350 fue aprobado y calificado como consumible para hacer reparaciones con soldadura de rieles grado R350HT ya que cumple los requisitos de cordón único, capa única y multicapas establecidos en las normas UNE-EN 13674-1:2012 y 15594:2009: su dureza superficial fue de $417 \pm 10$ quedando en el rango de $370-423 \mathrm{HV}$ y su dureza sub-superficial en los primeros $10 \mathrm{~mm}$ fue de $396 \pm 9 \mathrm{HV}$ que está en el rango admisible por la norma de 358-412 HV.

Para más de cuatro capas la dureza sub-superficial de la primera capa y la ZAT cae por debajo de la dureza del riel R350HT, por lo que el DUR 350 serviría para hacer recargues menores o iguales que $10 \mathrm{~mm}$ (aproximadamente tres capas), lo cual resultaría suficiente para las reparaciones ordinarias de superficies de rodadura de ferrovías. El requisito de la norma UNE-EN 15594-1:2009 de hacer pruebas con soldaduras superficiales de cinco capas resulta muy complicado de cumplir, si no imposible, debido al reblandecimiento de las capas asociado a los múltiples ciclos térmicos. 


\section{AGRADECIMIENTOS}

Los autores desean agradecerle especialmente a la Universidad Nacional de Colombia, Sede Medellín, y al Instituto Tecnológico Metropolitano por el soporte en infraestructura de laboratorios y de financiación que posibilitaron el desarrollo de este proyecto, al igual que a la empresa de transporte masivo METRO de Medellín.

\section{BIBLIOGRAFÍA}

[1] Asociación Española de Normalización y Certificación. Norma UNE-EN 13674-1:2012 Aplicaciones ferroviarias - Vía - Carriles - Parte 1: Carriles Vignole de masa mayor o igual a 46 kg/m. España: AENOR; 2012.

[2] Pointner P. Definitive guidelines on the use of different rail grades. China: Innotrack; 2009.

[3] Heyder R. Rail Materials - Alternatives and limits. Korea: Research Gate; 2008.

[4] Lewis R. Wheel-rail interface handbook. Cambridge: Elsevier; 2009. http://dx.doi.org/10.1533/9781845696788.

[5] Girsch G. Advanced rail steels for Heavy Haul application - track performance and weldability. Shanghai: IHHA; 2009. pp. 3-5.

[6] Singh S. Rails for heavy axle load operations. Lucknow: ED/Track-I/RDSO; 2009. pp. 12-13.

[7] Girsc G, Frank N. New rail grades - A technical performance overview. In: Proceedings of the 8th International Heavy Haul Conference; 2005 June 14-16; Rio de Janeiro. Rio de Janeiro; 2005.

[8] R. Heyder. Testing of HSH rails in high - Speed tracks to minimize rail damage. Wear. 2003;258:1014-1021.

[9] American Welding Society. AWS D15.2: Recommended practices for the welding of Rails and related rail components for use by rail vehicles. Miami, FL: American Welding Society; 2003.

[10] Red Nacional de Ferrocarriles Españoles. RENFE NRV 3-0-3.1. Reparación de la superficie de rodadura por recargue al arco eléctrico. España: RENFE; 1994.

[11] Asociación Española de Normalización y Certificación. Norma UNE-EN 15594:2009 Aplicaciones ferroviarias - Vía - Reparación de carriles por soldeo por arco eléctrico. España: AENOR; 2010.

[12] American Society of Mechanical Engineers. ASME Boiler and Pressure Vessel Code - Section V: Nondestructive Examination. New York, NY: ASME; 2015.

[13] Asociación Española de Normalización y Certificación. UNE-EN 13674-1, Aplicaciones ferroviarias - Vía - Carriles - Parte 1: Carriles Vignole de masa mayor o igual a $46 \mathrm{~kg} / \mathrm{m}$. Madri: AENOR; 2012.

[14] VoestAlpine. Welding recommendation for Vignol and Grooved rails. Linz, Áustria: VoestAlpine; 2017.

[15] Funderburk RS. Selecting filler metals: matching strength criteria. Welding Innovation. 1999;16(2):1-3.

[16] Asociación Española de Normalización y Certificación. UNE EN 14700: Consumibles para el soldeo - Consumibles para el soldeo para recargue duro. Madri: AENOR; 2014.

[17] American Welding Society. AWS A5.13: Specification for surfacing electrodes for shielded metal ARC Welding. Miami, FL: AWS; 2000.

[18] Kandeva-Ivanova M, Vencl A, Karastoyanov D. Advanced tribological coatings for Heavy-duty applications: case studies [monograph]. Sofia, Bulgaria: Bulgarian Academy of Sciences, Institute of Information and Communication Technologies; Prof. Marin Drinov Publishing House of Bulgarian Academy of Sciences; 2016.

[19] Easterling, K. Introducción a la física metalúrgica de la soldadura. Oxford: Heinemenn; 1992. pp. 18-19.

[20] Tsai NS, Eagar TW. Selection of processes for welding steel rails. In: Proceedings in Railroad Rail Welding, Railway Systems and Management Association, Northfield, NJ, 1985. 421-435 